Thành phố Hồ Chí Minh, 2008, tr.237 - 239.

4. Kỹ thuật bào chế và chế biến thuốc cổ truyên: Phùng Hoà Bình, Phạm Xuân Sinh. Võ Xuân Minh, Vũ Văn Điền, Nhà xuất bản Y học, Hà Nội, 2004, tr.7 - 10, 69 - 70, 83 - 103.
5. Phương tễ họ: Hoàng Duy Tân, Nhà xuất bản Thuâan Hoá, 200̄9, tr.642 - 647.

6. Phương thuốc cố truyên: Hoàng Bảo Châu, Nhà xuất bản Y học, Hà Nội, 1998, tr.173 - 174.

7. Y lý Y hoc cố truyền: Nguyễn Thi Tân, Nhà xuất bản Đại học Huế, 2015, tr.13 - 28.

\title{
KIẾN THỨC VÀ THƯC HÀNH CHĂM SÓC TRƯỚC SINH CỦA CÁC THAI PHU CÓ TUỔI THAI TỪ ĐỦ 37 TUẦ TRỞ LÊN TẠI TRUNG TẨM Y TẾ HUYÊ̂N XUÂN LộC, ĐỒNG NAI
}

\section{TÓM TẮT}

Đăt vấn đề: Chăm sóc trước sinh là những chăm sóc mà thai phụ nhận được nhằm đảm bảo những điều kiện tốt nhất về sức khỏe cho cả me và thai trong suốt thai kỳ. Chăm sóc trước sinh có vai trò quan trọng trong việc giảm tỷ lệ tử vong me và tử vong sơ sinh trên thế giới, đặc biệt là ở các quốc gia đang phát triển. Nghiên cứu được tiến hành nhằm khảo sát thực trạng kiến thức và thực hành chăm sóc trước sinh cửa các thai phụ tại Huyện Xuân Lộc, Đồng Nai. Hiện vẫn chưa có nghiên cứu về vấn đề chăm sóc trước sinh tại địa phương. Mục tiêu: Xác định tỷ lệ thai phụ đi khám thai tối thiểu 4 lần và tỷ lể thai phụ có kiến thức tốt, hành vi đúng về chăm sóc trước sinh tại Trung tâm $Y$ tế Huyện Xuân Lộc. Phương pháp nghiên cứu: Thiết kế nghiên cứu cắt ngang được thực hiện từ 11/2020 đến 05/2021 trên 332 thai phụ có tuổi thai từ đủ 37 tuần trở lên đến khám tại TTY̛T Huyện Xuân Lộc, với điểm cắt $75 \%$ được sử dụng để xác định mức độ kiến thức tốt hoặc thực hành đúng về chăm sóc trước sinh của các thai phụ. Kết quả: Tỷ lệ thai phụ đi khám thai tối thiểu 4 lân trong thai kỳ là $86,4 \%$. Tỷ lệ thai phụ có kiến thức tốt về chăm sóc trước sinh là $89,5 \%$. Tỷ lệ thai phụ có thực hành đúng về chăm sóc trước sinh là 87,6\%. Kết luận: Tỷ lệ thai phụ đi khám thai tối thiểu 4 lần trong thai kỳ cững như tỷ lệ thai phụ có kiến thức tốt, hành vi đúng về chăm sóc trước sinh đều cao hơn tỷ lệ chung của cả nước. Tuy nhiên, kiến thức của thai phụ về các vấn đề dinh dướng, lao động và nghỉ ngơi trong thai kỳ vẫn chưa thực sự tốt. Cẩn tiếp tục tăng cường các biện pháp giáo dục, truyền thông và tư vấn để cải thiên các khía canh còn hạn chế của chương trình chăm sóc trước sinh tại địa phương.

Tư khóa: kiến thức, thực hành, chăm sóc trước sinh, thai phụ.

\section{SUMMARY \\ KNOWLEDGE AND PRACTICE REGARDING}

\footnotetext{
${ }^{1}$ Trung tâm Y tế Huyện Xuân Lộc, Đồng Nai

2Đai hoc Y Dướ TPHCM

Chịu trách nhiệm chính: Trần Lệ Thủy

Email: tranlethuy@ump.edu.vn

Ngày nhận bài: 9.8.2021

Ngày phản biên khoa hoc: 8.10.2021

Ngày duyệt bài: 15.10 .2021
}

Trần Đình Chắt ${ }^{1}$, Trần Lệ Thủy ${ }^{2}$

\section{ANTENATAL CARE AMONG PREGNANT WOMEN AT OR BEYOND 37 0/7 WEEKS OF GESTATION IN XUAN LOC HEALTH CENTER, DONG NAI PROVINCE}

Background: Antenatal care (ANC) is the care a women receives throughout pregnancy in order to ensure that both the mother and her child remain healthy. ANC plays an important role in reducing maternal and neonatal morbidity and mortality, especially in developing countries. This study aims to assess the conditions of knowledge and practice toward ANC among pregnant women in Xuan LoC District, Dong Nai Province. There are currently no studies on prenatal care in this area. Objectives: Determine the proportion of pregnant women receiving at least four (ANC4+) visits. We also determine the proportion of pregnant women having good knowledge and correct practice regarding ANC at Xuan Loc Health Center. Methods: A cross-sectional study was conducted on 332 pregnant women, who have gestational age at or beyond $370 / 7$ weeks and checking-up ANC at Xuan Loc Health Center from November 2020 to May 2021. Beside assessing the frequency of ANC visits, we also use the cut-off point at $75^{\text {th }}$ percentage to determine the level of knowledge and practice regarding ANC of these womens. Results: The percentage of pregnant women having at least four or more ANC visits is $86.4 \%$. Among 332 pregnant women, we found that $89.5 \%$ have good knowledge while $87.6 \%$ of them were noted to have correct practice about ANC. Conclusion: Our research's results about the proportion of pregnant women either receiving ANC4+ visits or having good knowledge and correct practice toward ANC are higher than the total proportion of country. However, the level of knowledge of pregnant women regarded the importance of nutrition and how they work or sleep during pregnancy were poor. These findings can be used to plan a social media and education campaign-based customized health intervention aiming to improve the limited aspects of local ANC program.

Keywords: Knowledge, Practice, Antenatal care, Prenatal care, Pregnant women.

\section{I. ĐĂT VẤN ĐỀ}

Thai nghén là một hiện tượng sinh lý bình 
thường của người phụ nữ. Tuy nhiên, trong quá trình mang thai, nhiều yếu tố bình thường có thể trở thành yếu tố nguy cơ hoặc diễn tiến thành bệnh lý và ảnh hưởng đến sức khỏe, thậm chí là tính mạng của cả mẹ và thai. Theo số liệu của Tổ chức Y tế Thế giới (WHO) năm 2017, mỗi năm trên thế giới có khoảng 300,000 thai phụ tử vong vì các vấn đề liên quan đến thai kỳ, trong đó hơn $99 \%$ là xảy ra ở các nước đang phát triển và hầu hết nguyên nhân là đều có thể phòng ngừa được ${ }^{(1)}$. Còn theo số liệu của Quỹ Nhi đồng Liên Hợp Quốc (UNICEF) năm 2019 thì mỗi năm cũng có gần 2,5 triệu trẻ sơ sinh tử vong trên thế giới(2). Số liệu này ở Việt Nam lần lượt là 700 bà me và 17,000 trẻ sơ sinh tử vong mỗi năm(1),(2). Từ lâu, các nội dung làm me an toàn nói chung và chăm sóc trước sinh (CSTS) nói riêng đã được chứng minh là có hiệu quả cao trong việc giảm tỷ lệ tử vong me và sơ sinh một cách trực tiếp lẫn gián tiếp. Để đạt được những lợi ích đó, thai phụ phải đi khám thai đầy đủ khi mang thai để được quản lý thai nghén tốt, đồng thời còn được trang bị những kiến thức cơ bản như số lần khám thai tối thiểu, thời điểm khám thai, nội dung mối lần khám, về chế độ dinh dưỡng, lao động, nghỉ ngơi hợp lý cũng như khả năng nhận biết được các dẩu hiệu nguy hiểm cần đi khám ngay trong thai kỳ.

ở Việt Nam, mặc dù chất lượng chăm sóc trước sinh cũng như tỷ lệ tử vong me và sơ sinh đã được cải thiện nhiêu trong khoảng ba thập niên vừa qua nhưng gần đây, tốc độ giảm tử vong me và sơ sinh bắt đâu chững lại và vẫn còn tương đối cao ở những khu vực miền núi, vùng sâu vùng xa hoặc vùng đồng bào dân tộc thiểu số sinh sống. Xuân Lộc là một huyện trung du miền núi của tỉnh Đồng Nai, điêu kiện kinh tế cũng như cơ sở hạ tâng kém phát triển hơn so với các địa phương khác trong tỉnh, trong vùng. Đây cũng là địa bàn sinh sống của một số nhóm dân tộc thiểu số như Chăm, Chơ-ro,....Mặ̆t khác, hiên vẫn chưa có bất kỳ nghiên cứu nào thực hiện khảo sát về tình hình chăm sóc trước sinh của các thai phụ trên địa bàn.

Do đó, chúng tôi tiến hành nghiên cứu "Kiến thức, thực hành chăm sóc trước sinh của các thai phụ có tuổi thai từ đủ 37 tuần trở lên đến khám tại Trung tâm $Y$ tế Huyện Xuân Lộc, Đồng Nai" để trả lời cho câu hỏi nghiên cứu "Tỷ lệ thai phụ có kiến thức tốt cũng như thực hành đúng vể chăm sóc trước sinh là bao nhiêu?".

Mục tiêu nghiên cứu: Xác định tỷ lệ thai phụ đi khám thai tối thiếu 4 lần và tỷ lệ thai phụ có kiến thức tốt cũng như thực hành đúng về chăm sóc trước sinh tại Trung tâm Y tế (TTYT) Huyện Xuân Lộc.

\section{II. ĐỐl TƯỢNG VÀ PHƯƠNG PHÁP NGHIÊN CỨU}

Đối tượng nghiên cứu. Thai phụ có tuổi thai từ 37 tuần trở lên đến khám thai hoặc đến sinh tại TTYT Huyện Xuân Lộc, Đồng Nai từ tháng $11 / 2020-05 / 2021$.

\section{Tiêu chuẩn lựa chọn:}

+ Thai phụ đến khám thai hoặc đến sinh tại khoa CSSKSS, TTYT Huyện Xuân Lộc.

+ Có tuổi thai từ đủ 37 tuần trở lên được xác nhận bằng siêu âm hoặc ngày kinh cuối.

+ Hiểu và giao tiếp tốt được bằng tiếng Việt. Nếu là người dân tộc thiểu số, cần có phiên dịch.

+ Đồng ý tham gia nghiên cứu.

\section{Tiêu chuẩn loại trừ:}

+ Không đồng ý tham gia nghiên cứu.

+ Có bệnh lý về tâm thần, khiếm thính, khiếm thị.

+ Khồng hiểu, không giao tiếp được bằng tiếng Việt hoặc không có người phiên dịch.

\section{Phương pháp nghiên cứu}

Thiết kế nghiên cứu. Nghiên cứu cắt ngang.

Cỡ mẫu. Công thức tính cõ̃ mẫu: ước lượng một tỷ lệ trong dân số.

$$
\mathbf{N}=Z_{1-\infty / 2}^{2} \cdot \frac{p(1-p)}{d^{2}}
$$

$\mathrm{p}=0,74$, với $\mathrm{p}$ là tỷ lệ thai phụ khám thai tối thiểu 4 lần theo MICS 2014(3).

$$
\mathrm{d}=0,05 \text { vì } 0,7<\mathrm{p}<0,9) . \rightarrow \mathrm{N}=296
$$

Địa điểm và thời gian nghiên cứu

+ Địa điểm nghiên cứu: Khoa CSSKSS, TTYT Huyện Xuân Lộc.

+ Thời gian nghiên cứu: từ 11/2020 05/2021.

\section{Phương pháp chọn mẫu}

\section{Chọn mấu ngấu nhiên thuận tiện.}

Công cự nghiên cứu. Bộ câu hỏi soạn sẵn, phỏng vấn trực tiếp thai phụ.

Biến số nghiên cứu. Biến số nghiên cứu gồm 3 nhóm chính: đặc trưng cá nhân, kiến thức và thực hành CSTS của thai phụ.

Biến số nghiên cứu chính là tỷ lệ thai phụ đi khám thai tối thiểu 4 lần trong thai kỳ và tỳ lệ thai phụ có kiến thức tốt và thực hành đúng về CSTS.

Tiêu chuẩn đánh giá. Biến số kiến thức CSTS gồm 10 nội dung, thai phụ sẽ được đánh giá là có kiến thức tốt về CSTS nểu trả lời đúng ít nhất 75\% (8 nội dung) trở lên. Tương tự, biến số thực hành CSTS gồm 9 nội dung, thai phụ được đánh giá là thực hành đúng về CSTS nếu thực hiện đúng ít nhất 75\% (7 nội dung) trở lên.

Thu thập và phân tích sổ liệu. Xác định chính xác tuổi thai dựa vào ngày kinh cuối hoặc 
kết quả siêu âm trong sổ khám thai tất cả các thai phụ đến khám.

Chọn những thai phụ có tuổi thai từ đủ 37 tuần trở lên và thỏa các tiêu chuẩn lựa chọn tham gia nghiên cứu.

Lấy xác nhận đồng ý tham gia nghiên cứu bằng văn bản.

Phỏng vấn trực tiếp thai phụ bằng bộ câu hỏi đã chuẩn bị sẵn trong khoảng thời gian 20 phút.

Sau khi thu thập số liệu, chúng tôi tiến hành tổng hợp, xử lý và phân tích số liệu bằng phần mềm STATA 10.0. Gồm 2 bước: thống kê mô tả và phân tích đơn biến; dùng mô hình hồi quy đa biến nhằm kiểm soát yếu tố gây nhiễu để xác định mối liên quan giữa các biến số và tính $P R$ hiệu chỉnh ( $\left.\mathrm{PR}^{*}\right)$ cho từng biến số. Các phép kiểm đều được thực hiện với độ tin câyy 95\%.

$\mathbf{Y}$ đức. Nghiên cứu này được thồng qua bởi Hội đồng Đạo đức trong nghiên cứu $Y$ sinh học Đại học Y Dược TP. HCM, số 791/HĐĐĐ-ĐHYD, ngày $02 / 11 / 2020$.

\section{KẾT QUẢ NGHIÊN CỨU}

Sau thời gian nghiên cứu từ $11 / 2020$ đến 05/2021 với số lượng mẫu thu thập được là 332 mẫu. Chúng tôi tiến hành nghiên cứu cắt ngang trên 332 thai phụ, kết quả đạt được như sau:

Đặc điểm cá nhân của đồi tượng nghiên cứu

Bảng 1: Đặc điểm cá nhân của đối tượng nghiên cứu

\begin{tabular}{|c|c|c|}
\hline Đặc điểm & $\begin{array}{c}\text { Tân số } \\
(\mathrm{N}=332)\end{array}$ & $\begin{array}{l}\text { Tỷ lệ } \\
(\%)\end{array}$ \\
\hline $\begin{array}{r}\text { Nhóm tuối: }<20 \\
20-34 \\
>35\end{array}$ & $\begin{array}{c}33 \\
251 \\
48\end{array}$ & $\begin{array}{l}9,9 \\
75,6 \\
14,5\end{array}$ \\
\hline 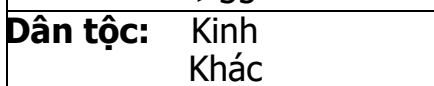 & $\begin{array}{c}286 \\
46\end{array}$ & $\begin{array}{l}86,1 \\
13,9\end{array}$ \\
\hline $\begin{array}{r}\text { Nghề nghiệp: Nông dân } \\
\text { Công nhân } \\
\text { CBVC } \\
\text { Khác }\end{array}$ & $\begin{array}{c}29 \\
219 \\
28 \\
56\end{array}$ & $\begin{array}{c}8,7 \\
66,0 \\
8,4 \\
16,9\end{array}$ \\
\hline $\begin{array}{c}\text { Trình độ học vấn: Cấp } 1 \\
\text { Cấp } 2 \\
\text { Cấp } 3 \\
\text { > Cấp 3 }\end{array}$ & $\begin{array}{c}31 \\
139 \\
126 \\
36\end{array}$ & $\begin{array}{r}9,3 \\
41,9 \\
38,0 \\
10,8\end{array}$ \\
\hline $\begin{array}{r}\text { Iân sinh } 0 \\
1 \\
2 \\
>2\end{array}$ & $\begin{array}{c}61 \\
137 \\
109 \\
25\end{array}$ & $\begin{array}{c}18,4 \\
41,3 \\
32,8 \\
7,5\end{array}$ \\
\hline
\end{tabular}

Đa số $(75,6 \%)$ các thai phụ nằm trong đô̂ tuổi từ $20-24$ tuổi. Hầu hết các thai phụ là người dân tộc Kinh với tỷ lệ $86,1 \%$ và phần lớn có nghề nghiệp là công nhân với tỷ lệ $66 \%$. Trình độ học vấn chủ yếu là đã học hết cấp 2 và cấp 3 với tỷ lệ lần lượt là $41,9 \%$ và 385 . Các thai phụ đã từng sinh con 1 và 2 lần chiếm đa số với tỷ lệ lần lượt là $41,3 \%$ và 32,8\%.

Kiến thức CSTS của đối tượng nghiên cứu

Bảng 2: Kiến thức của thai phụ về từng nội dung chăm sóc trước sinh

\begin{tabular}{|c|c|c|}
\hline Kiến thức & $\begin{array}{c}\text { Tân số } \\
(\mathbf{N}=332)\end{array}$ & \begin{tabular}{|c|} 
Tỷ lệ \\
biết(\%)
\end{tabular} \\
\hline Lợi ích khám thai & 332 & 100 \\
\hline $\begin{array}{l}\text { Số lần khám thai tối thiểu } \\
\text { (4 lần) }\end{array}$ & 312 & 94 \\
\hline $\begin{array}{l}\text { Khám thai lân đâu trong } \\
\text { TCN I }\end{array}$ & 305 & 91,9 \\
\hline $\begin{array}{c}\text { Các dấu hiệu nguy hiếm cần } \\
\text { đi khám ngay } \\
\text { Xuất huyết âm đạo } \\
\text { Đau bưng nhiều } \\
\text { Đau đâu kèm nhìn mờ } \\
\text { Co giật } \\
\text { Biết ít nhất } 2 \text { dấu hiệu }\end{array}$ & $\begin{array}{l}325 \\
290 \\
172 \\
146 \\
313\end{array}$ & $\begin{array}{l}97,9 \\
87,3 \\
51,8 \\
44,0 \\
94,3\end{array}$ \\
\hline Lợi ích tiêm phòng uốn ván & 282 & 85,0 \\
\hline Lợi ích bổ sung sắt/acid folic & 301 & 90,7 \\
\hline Dinh dưỡng khi mang thai & 217 & 65,4 \\
\hline Lao động khi mang thai & 280 & 84,3 \\
\hline Nghỉ ngơi khi mang thai & 268 & 80,7 \\
\hline $\begin{array}{l}\text { Thuốc lá, rượu bia có hại } \\
\text { cho thai }\end{array}$ & 325 & 97,9 \\
\hline
\end{tabular}

Kiến thức CSTS của thai phụ

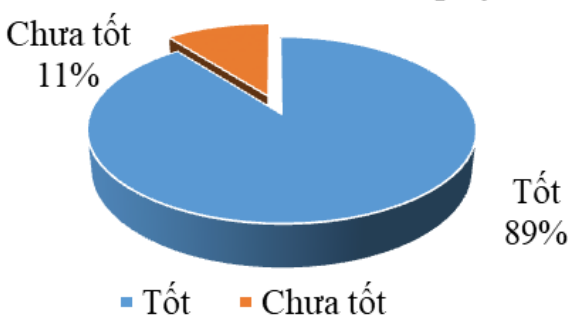

Biểu đồ 1: Tỷ lệ thai phụ có kiến thức tốt về tất cá các nôi dung CSTS

Khi sử dụng điểm cắt $75 \%$ (8 nội dung trở lên) chúng tôi ghi nhận tỷ lệ thai phụ có kiến thức tốt về CSTS là $89,5 \%$ và chỉ khoảng $10,5 \%$ thai phụ có hiểu biết chưa đủ, chưa tốt về CSTS.

Thực hành CSTS của đối tượng nghiên cứu

Bảng 3: Các hành vi CSTS của thai phu

\begin{tabular}{|c|c|c|}
\hline Hành vi & $\begin{array}{c}\text { Tân số } \\
(\mathbf{N}=332)\end{array}$ & $\begin{array}{c}\text { Tỷ lệ̂ } \\
\text { đứng } \\
(\mathbf{\%})\end{array}$ \\
\hline $\begin{array}{c}\text { Số lần khám thai thực tế } \\
\text { >=4 lần }\end{array}$ & 287 & 86,4 \\
\hline $\begin{array}{c}\text { Thời điếm khám thai lần đầu } \\
\text { trong TCN I }\end{array}$ & 324 & 97,6 \\
\hline $\begin{array}{c}\text { Khám thai đúng lịch } \\
\text { 11-13 tuần }\end{array}$ & 321 & 96,7 \\
\hline \multicolumn{2}{|c|}{} \\
\hline
\end{tabular}




\begin{tabular}{|c|c|c|}
\hline 20-24 tuân & 308 & 92,8 \\
30-32 tuần & 229 & 69,0 \\
Đúng ít nhất 2 thời điểm & 316 & 95,2 \\
\hline Nơi khám thai (Cơ sở y tế) & 332 & 100 \\
\hline Tiêm phòng uốn ván đủ & 310 & 93,4 \\
\hline Uống viên sắt/folic & 329 & 99,1 \\
\hline Chế độ dinh dưỡng phù hợp & 147 & 44,3 \\
\hline Chế độ lao động phù hợp & 261 & 78,6 \\
\hline Chế độ nghì ngơi phù hợp & 259 & 78,0 \\
\hline
\end{tabular}

Thực hành CSTS của thai phụ

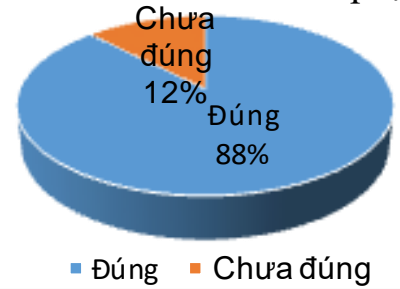

Biêu đồ 2: Tỷ lệ thai phụ thực hành đúng tất cả các nôi dung về CSTS

Khi sử dụng điểm cắt $75 \%$ ( 7 nội dung trở lên) chúng tổi ghi nhận tỷ lệ thai phụ thực hành CSTS đúng là $87,6 \%$ và chỉ khoảng $12,4 \%$ thai phụ thực hành CSTS chưa phù hợp, chưa đúng trong thai kỳ.

\section{BÀN LUÂN}

Kiến thức CSTS của các thai phụ. Với $94 \%$ các thai phụ cho rằng cần đi khám thai tối thiểu 4 lần trong thai kỳ, kết quả của chúng tôi gần tương đồng với nghiên cứu của Phạm Văn Dậu ${ }^{(4)}$ là $90,8 \%$. Gần $92 \%$ các thai phụ cũ̃ng cho rằng nên đi khám thai lần đâu tiên trong 3 tháng đầu, tỷ lệ này cũng gần tương đồng với nghiên cứu của $\mathrm{Ngô}$ Viết Lộc(5) là 87,5\%. Nghiên cứu của chúng tôi ghi nhận $94,3 \%$ các thai phụ biết được ít nhất 2/4 dẩu hiệu nguy hiểm cần đi khám ngay. Tác giả Ngô Viết Lộc ${ }^{(5)}$ sử dụng điểm cắt là 3 dấu hiệu thì tỷ lệ này khá thấp với $82,6 \%$ còn tác giả Mai Thị Kim Thanh ${ }^{(6)}$ sử dụng điểm cắt là 1 dấu hiệu thì đạt được tỷ lệ rất cao là $98,3 \%$. Tỷ lệ thai phụ biết về lợi ích tiêm VAT trong thai kỳ đạt $85 \%$, kết quả này khá tương đồng với nghiên cứu của Mai Thị Kim Thanh ${ }^{(6)}$ là $90,7 \%$ và Sitalakshmi (7) ở Ấn Độ là $92 \%$. Tỷ lệ thai phụ có hiểu biết về lợi ích bổ sung sắt/acid folic trong thai kỳ là $90,7 \%$, tỷ lệ này cao hơn so với nghiên cứu của Pham Văn Dậu( ${ }^{(4)}$ là $83,6 \%$, nhưng lại khá tương đồng với nghiên cứu của Sitalakshmi(7) ở Ấn Độ là 89,8\%.

Ngoài ra, trong nghiên cứu của chúng tôi có $65,4 \%$ các thai phụ cho rằng cần thay đổi chế độ dinh dưỡng, 84,3\% thai phụ biết về chế độ lao động đúng khi mang thai. Theo nghiên cứu của
Ogunba ${ }^{(8)}$ ở Nigeria thì các tỷ lệ này lần lượt là $79,2 \%$ và $55 \%$. Chúng tôi cũng ghi nhận có $80,7 \%$ thai phụ biết về chế độ nghỉ ngơi hợp lý khi mang thai, tỷ lệ này cao hơn nhiêu so với nghiên cứu của Sitalakshmi ${ }^{(7)}$ ở Ấn Độ với chỉ khoảng 39\%.

Tóm lại, tỷ lệ thai phụ có kiến thức tốt về tất cả các nội dung chăm sóc trước sinh trong nghiên cứu của chúng tôi đạt tỷ lệ $89,5 \%$. Tỷ lệ này cao hơn nhiều so với nghiên cứu của Ngố Viết Lộc ${ }^{(5)}$ là $60,3 \%$. Sự khác biệt kết quả với tác giả trong nước có thể là vì các nghiên cứu này sử dụng thiết kế nghiên cứu và biến số nghiên cứu khác với chúng tôi, nghiên cứu của chúng tôi khảo sát kiến thức liên quan đến tất cả các nội dung CSTS mà các nghiên cứu khác ít thực hiện bao gồm cả chế độ dinh dưỡng, lao động và nghỉ ngơi trong thai kỳ.

Thực hành CSTS của các thai phụ. Tỷ lê thai phụ đi khám thai tối thiểu 4 lần trong nghiên cứu của chúng tôi đạt $86,4 \%$. Tỷ lệ này cao hơn so với tỷ lệ chung của cả nước là $74 \%$ nhưng lại tương đồng với tỷ lệ của vùng Đông Nam Bộ là $90 \%$ theo kêt quả của MICS 2014(3). Về tỷ lệ thai phụ đi khám thai lần đầu trong tam cá nguyệt I, nghiên cứu của chúng tôi cũng ghi nhận tỷ lệ này khá cao với $97,6 \%$. Theo MICS 2014(3) thì tỷ lệ này cao hơn tỷ lệ chung cả nước $(84,7 \%)$ nhưng khá tương đồng với tỷ lệ của vùng Đông Nam Bộ là 93,1\%. Tỷ lệ thai phụ thực hành tiêm VAT đủ số lần là $93,4 \%$. Tỷ lệ này cũng gần tương đồng với nghiên cứu của Mai Thị Kim Thanh(6) là $96,4 \%$ và Nguyễn Thị Mỹ Hương( ${ }^{(9)}$ là gần $98 \%$. Tỷ lệ thai phụ có bổ sung viên sắt/folic trong thai kỳ đạt $99 \%$. Kết quả của chúng tôi tuy cao hơn tỷ lệ chung của cả nước theo kết quả MICS $2014^{(3)}$ là $82 \%$ và nghiên cứu của Nguyễn Thị Mỹ Hương( ${ }^{(9)}$ là $91 \%$ nhưng lại khá tương đồng với nghiên cứu của Phạm Văn Dậu(4) là $94,7 \%$ và Mai Thị Kim Thanh'(6) là 94,8\%. Chỉ khoảng $44,3 \%$ thai phụ có chế độ dinh dưỡng phù hợp khi mang thai, tỷ lệ này cao hơn so với nghiên cứu của Nguyễn Thị Mỹ Hương( ${ }^{(9)}$ là $29 \%$. Tỷ lệ thai phụ có chế độ lao động hợp lý khi mang thai là $78,6 \%$, cũng khá tương đồng với nghiên cứu của Nguyễn Thị Mỹ Hương(9) là $82 \%$. Ngoài ra, nghiên cứu của chúng tôi cũng ghi nhận có khoảng $78 \%$ thai phụ có chế độ nghỉ ngợi phù hợp, ngủ ít nhất 8 giờ mỗi ngày trong thai kỳ.

Nhìn chung, tỷ lệ thai phụ có thực hành đúng về tất cả các nội dung CSTS trong nghiên cứu của chúng tôi là $87,6 \%$. Tỷ lệ này cũng hoàn toàn tương đồng với nghiên cứu của Ngô Viết 
Lộc ${ }^{(5)}$ là $86 \%$.

Hạn chế của đề tài. Việc sử dụng thiết kế nghiên cứu cắt ngang, không phải là thiết kế cho năng lực mẫu mạnh làm hạn chế khả năng khảo sát mức độ liên quan nhân quả giữa các yếu tố.

\section{KẾT LUÂNN}

Trong thời gian 7 tháng thực hiện nghiên cứu trên 332 thai phụ có tuổi thai đủ 37 tuân trở lên tại TTYT Huyện Xuân Lộc, chúng tôi ghi nhận được:

Tỷ lệ thai phụ đi khám thai tối thiểu 4 lân trong thai kỳ là 86,4\%.

Tỷ lệ thai phụ có kiến thức tốt về các nội dung CSTS là $89,5 \%$.

Tỷ lệ thai phụ thực hành đúng các nội dung về CSTS là $87,6 \%$.

\section{TÀI LIÊU THAM KHẢO}

1. WHO, (2019), Trends in maternal mortality 2000 to 2017: estimates by WHO, UNICEF, UNFPA.

2. UNICEF, (2019), The state of the world's children 2019: children, food and nutrition, New York.

3. Tổng cục Thống kê, UNICEF, (2015), Điều tra đánh giá các mục tiêu trẻ em và phụ nữ Việt Nam 2014, Báo cáo cuối cùng, Hà Nội.
4. Phạm Văn Dậu, Phạm Câm Kỳ, Bùi Thị Hương, (2021), "Thực trạng kiến thức và thực hành làm me an toàn của các bà me sinh con tai cơ sở y tế công trên địa bàn tỉnh Ninh Bình năm 2019", Tap chí Y hoc Cônng đồng, 62 (1), 146-151.

5. Ngô Viểt Lộc, Lế Thị Thanh Huyên, (2017), "Kiến thức vâ thực hành về chăm sóc thai sản tai huyện Hòa Vang, thành phố Đà Nẵng năm 2015", Tap chí Y học Thành phố Hồ Chí Minh, 21 (1), 49-53.

6. Mai Thi Kim Thanh, (2017), "Kiến thức thực hành chăm sóc trước sinh của các bà me có con nhỏ dưới 1 tuổi tại huyện Buôn Đôn và Cư Kuin tỉnh Đắk Lắk năm 2016", Tạp chí Y học Việt Nam.

7. Sitalakshmi $\mathbf{V}$, Bavyasri $P$, Talapala $R$, Kopperla M, (2020), "Study on knowledge, attitude and practice of ante-natal care among pregnant women attending antenatal tertiary care institution", International Journal of Reproduction, Contraception, Obstetrics and Gynecology; Vol 9, No 3 (2020): March 2020.

8. Ogunba B O, Abiodun O B, (2017), "Knowledge and attitude of women and its influence on antenatal care attendance in Southwestern Nigeria", J Nutr Health Sci, 4 (2), pp. 207.

9. Nguyển Thị Mỹ Hương, Châu Khắc Tú, Trân Thị Lệ Hà, Ngô Hoàng Hiếu, (2015), "Đánh giá tình hỉnh chăm sóc trước sinh của các sản phu đến sinh tại Khoa Phụ Sản Bệnh viện Trung ương Huế", Tạp chí Phụ sản, 13 (3), 76-78.

\section{ĐÁNH GIÁ HIÊUU QUẢ KÉO DÀI GIẢM ĐAU SAU MỔ LẤY THAI BẰNG GÂY TÊ MẠT PHẲNG CO' NGANG BUUNG BẰNG HỖN HỢP THUỐC ROPIVACAIN PHỐI HỢP VỚI DEXAMETHASON}

\section{Nguyễn Thị Thùy Dương ${ }^{1}$, Nguyễn Đức Lam $^{2}$, Nguyễn Thị Thanh ${ }^{3}$}

\section{TÓM TẮT}

Một nghiên cứu thử nghiệm lâm sàng ngẫu nhiên có đối chứng được thực hiện nhằm đánh giá hiệu quả kéo dài giảm đau sau mố lấx thai bằng gây tê mặt phẳng cơ ngang bung bằng hôn hợp thuốc ropivacain phối hợp với dexamethason. Nghiên cứu được thực hiên trền 100 bênh nhân tại Bênh viên Phu sản Hà Nội. Kết quả nghiên cứu cho thấy, thời gian giải cứu cớn đau đâu tiên ngắn hơn đáng kể ở nhóm $1(11,01$ $\pm 3,62$ giờ) so với nhóm $2(18,54 \pm 4,15$ giờ $)(p<0,05)$. Tổng nhu cầu morphin trong 24 giờ đâu sau phẩu thuật cao hơn đáng kể ở nhóm $1(5,62 \pm 2,1 \mathrm{mg})$ so với nhóm $2(4,07 \pm 1,9 \mathrm{mg})(\mathrm{p}<0,05)$. Điểm số VAS- $S$ và VAS- $V$ của cả hai nhóm khác nhau không đáng kể tại các thời điểm 1 giờ, 2 giờ và 4 giờ sau phấu thuật,

${ }^{1}$ Bênh viên Sản Nhi Lào Cai

2Trường Đại học Y Hà Nội

${ }^{3}$ Trung tâm Y tế Từ Sơn, Bắc Ninh

Chịu trách nhiệm chính: Nguyễn Thị Thùy Dương

Email: thuyduonggaymelaocai@gmail.com

Ngày nhận bài: 10.8.2021

Ngày phản biện khoa học: 11.10.2021

Ngày duyệt bài: 19.10.2021 tuy nhiên ở nhóm 1 cao hơn đáng kể so với nhóm 2 tai các thời điểm 8 giờ, 12 giờ, 16 giờ và 24 giờ sau phẫu thuật.Tỷ lệ nôn ở nhóm 1 chiếm $20 \%$ cao hơn nhiêuu so với nhóm 2 chỉ chiếm $4 \%, \mathrm{p}<0,05$. Các chì số lâm sàng liên quan đến tuần hoàn trong giới hạn bình thường và tương đương nhau giữa hai nhóm ở các thời điếm 1 giờ, 2 giờ , 4 giờ nghiên cứu. Nhịp tim, huyết áp trung bình lúc 8 giờ, 12 giờ, 16 giờ và 24 giớ sau phâu thuất ở nhóm 1 cao hơn đáng kể so với bệnh nhân nhóm $2(p<0,05)$. Các chỉ số lầm sàng liên quan đến hô hấp trong giới hạn bình thường và tương đương nhau giữa hai nhóm ở tất cả các thời điểm nghiên cứu. Trong nghiên cứu của chúng tôi không gặp bất kỳ tai biến nào liên quan đến gây tê TAP block.

Tư khóa: giảm đau, mổ lấy thai, ropivacain, dexamethason

\section{SUMMARY}

EVALUATION OF THE LONG-TERM

EFFECTIVENESS OF ANALGESIA AFTER CESAREAN SECTION BY LOCAL ANESTHESIA OF THE TRANSVERSE ABDOMINIS MUSCLE WITH A COMBINATION OF ROPIVACAINE AND DEXAMETHASONE 